\title{
ENVIRONMENTAL AND OVERALL APPRAISAL OF HIGHWAY STRUCTURES AND EARTHWORKS
}

\author{
K. FOTINI \\ Department of Civil Engineering of AUTH, Thessaloniki, Greece.
}

\begin{abstract}
Environmental constraints constitute, nowadays, a basic element of highway design, especially in view of the alignment optimization procedure into mountainous landscape. The route selection in these areas tackles to different problems of the overall project realization: earthwork volume, environmental protection, construction cost. As a general rule, the designer has to conceive an optimum alignment reducing earthwork volume and environmental impact all by providing a high serviceability level for the highway and to implement different geostructures for cut and fill sections. The assessment and the choice of the best environment-friendly geostructures is the result of the balancing out of technical, environmental, and economic parameters. An attempt to treat these issues using a rational and experimental analysis is hereafter presented.
\end{abstract}

Keywords: environmental protection, geostructures methods.

\section{INTRODUCTION}

Environmental constraints constitute, nowadays, a basic element of highway design, especially in view of the alignment optimization procedure into mountainous landscape. The route selection in these areas tackles to different problems of the overall project realization: earthwork volume, environmental protection, and construction cost.

As a general rule, the designer has to conceive an optimum alignment reducing earthwork volume and environmental impact all by providing a high serviceability level for the highway. This fundamental concept of design for projects of major importance is somehow contradictory and tends to be embarrassing. A high serviceability level is achieved by application of a high design speed, which leads to a strained alignment and significant earthwork operations. These operations are often prohibited by road authorities and therefore, the designer is obliged to suggest other solutions as bored tunnels, 'cut and cover' tunnels, reinforced earth structures, 'cover and cut' structures.

There are three important issues related to the adoption of these, so-called alternative techniques. The first one deals with the applicability and the suitability of these techniques, regarding engineering effectiveness and environmental impact. Within this issue, the basic question is if these techniques are, indeed, preferable to the conventional cutting and filling operations. The second one deals with the environment-friendliness of each structure or geostructure and their ability for integration in the existing landscape. The third deals with their comparative environmental performance.

Concerning the applicability of an alternative solution, the road designer should clearly take into account that regardless of the construction method, excavation materials will be produced throughout the construction stage. It is absolutely necessary to absorb them in fill structures along the highway instead of establishing deposit areas in ecologically sensitive regions. Therefore, the designer has to handle the question of exceeding excavation materials before prescribing other environment-friendly techniques, such as reinforced earth embankments or viaducts.

Another interesting point is the comparative environment-friendliness of each structure. Are there means to improve their environmental performance and which are the criteria and indicators that determine the environmental planning? 
Concerning the real environmental value of each of the afore-mentioned techniques, it is widely known and generally admitted that concrete structures, such as tunnels and viaducts, are less detrimental to the environment than the traditional road earthwork. Nevertheless, it is questionable whether these concrete structures are, indeed, absolutely environment-friendly and should be applied to replace cuttings and embankments of important offset.

An attempt to treat these issues using a rational and experimental analysis is hereafter presented.

\section{STRUCTURES AND EARTHWORKS}

A rational method for route selection creates minimum effect on landform and requires small volume of earthwork. In current practice, however, the alignment design (horizontal and vertical) produces, in some cases, significant physical impacts on the existing landscape. While optimizing road design, the shape of excavation can be planned so as to meet the economy, environmental, and aesthetic criteria.

Road alignment and design of earthworks should respond to the broad scale of the area topography as well as to the small scale of the landscape. Wherever topography is steep or undulating, namely regular rising and falling sides, the process of a high serviceability road design results in cuts and embankments with a wide landtake and unacceptable impact on the landscape.

The form and the slopes of the existing topography determine the earthwork operations and the estimated volume of cut and fills. The designer should take into consideration the basic rule of the volume of earthworks: in undulating landscape the ideal statement is that cut should equal fill. This is practicable only if all excavation material is suitable as fill. Earthworks have to provide a formation suited to the vertical alignment of a road and ensure that surface water flow is adequately accommodated in the resulting altered landform. The need for the least disturbance to the existing landscape is also an imperative need.

Different types of road geostructures are implemented in order to achieve stable slopes and restorable solutions (Fig. 1). The final choice of the implementation of each method depends on different parameters such as soil properties (organic matter content, water content); angle, type, and aspect of the natural slope; disturbance to natural terrain; volume of earthworks; utilization of waste materials; extent landtake; economy; and energy efficient design. The assessment and the choice of the best environment-friendly geostructures is the result of the balancing out of technical, environmental, and economic parameters.

\section{FILL SECTIONS}

Embankments are constructed from compacted material to slopes providing stability and excluding the possibility of landslides. The gradients of slope are 1:1 to 1:3, depending on the quality of material and the height of the earthwork. The gradient most widely applied is 1:1.5. The creation of bare, steep slopes that are exposed to the direct action of rainfall and high rates of water erosion is a significant problem. The role of vegetation is important in order to control soil loss and runoff and stabilize the slopes. One of the main practices to reclaim and establish grass is hydroseeding, that is spraying a mixture of water, seeds, fertilizers, fixing substances, and mulches. Hydroseeding is unsuitable for stabilizing steep slopes $(>1: 1)$, because the probability of seeds moving downhill is high. Gentle slopes $(<1: 2)$ make it easier to establish vegetation and provide integration with the surrounding landscape [1].

In case right-of-way available is limited or fill materials are unstable alternative solutions are preferred, as reinforced embankments or modular walls. An engineer needs to examine cost effectiveness, technical suitability, and appearance appropriate to their location. 


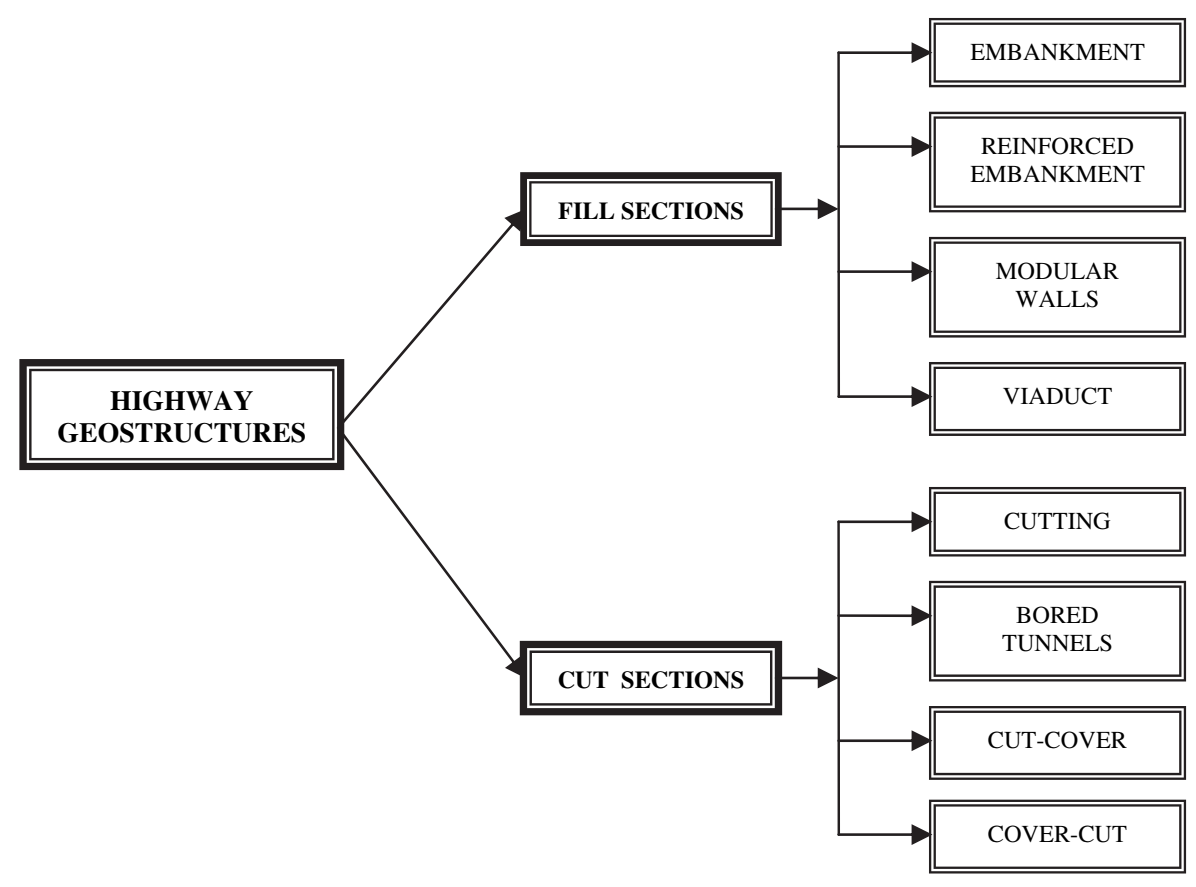

Figure 1: Different geostructures methods.

The evident advantages of a reinforced soil embankment compared to a traditional structure are: an environmentally vital space saving at the base, an increase in the resistance of erosion effects, and better energy absorption with minimum possibility of sliding. The reinforcement should enable the construction of the embankments with slopes steeper than 1:1.5, but the protection of the slopes from erosion effects is also necessary.

Retaining modular walls are necessary on space-constrained sites. Textures and finishes should reflect the context of the road landscape. Planting can soften the appearance of retaining walls but only where the right conditions for plant growth really exist.

The use of reinforced earth techniques allows construction of slopes well above the natural angle but they are more expensive compared to the traditional earthworks retaining structures. For example, retaining structures using interlocking grid or wood or concrete beams as barricades cost five times the cost of vegetation, the use of geotextiles membranes is about ten to twenty times the cost of vegetation, and retaining walls are the most expensive solution [2].

Generally, from an environmental point of view, the grading out of earthworks can provide integration with the surrounding landscape, whilst ensuring the most efficient use of material.

\section{EMBANKMENT VS VIADUCT}

Embankment and viaduct are two alternative kinds of infrastructures across valley. The economic choice between an embankment and a viaduct is determined by the volume and nature of available fill material for the embankment and by foundation conditions and width and number of spans for a viaduct. Embankments are generally implemented, as technical solution, in shallow and wide valley, while viaduct in narrow and steep valley. The final choice of implementation is under the process of weighing up costs and benefits. 


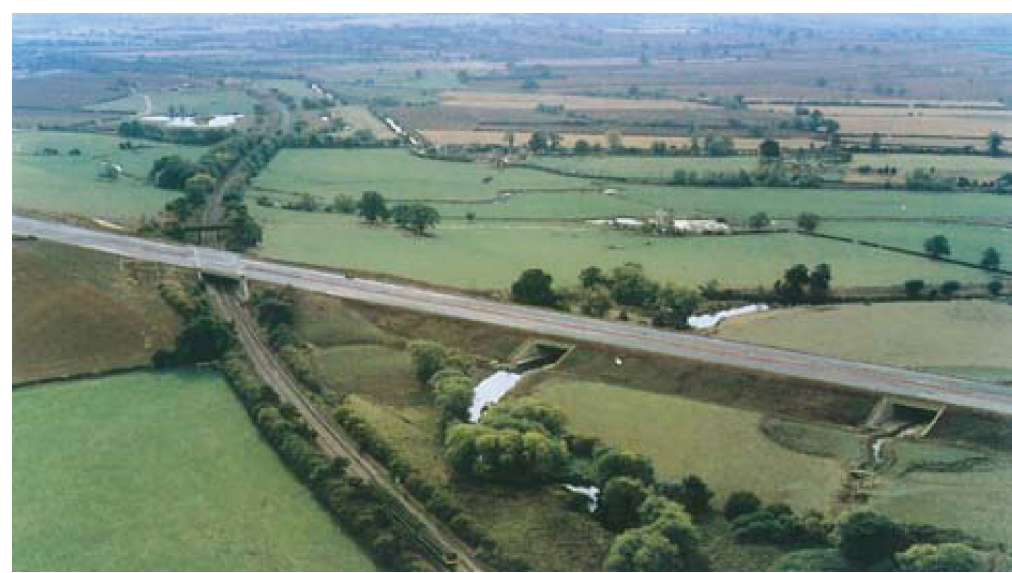

Figure 2: An embankment across valley.

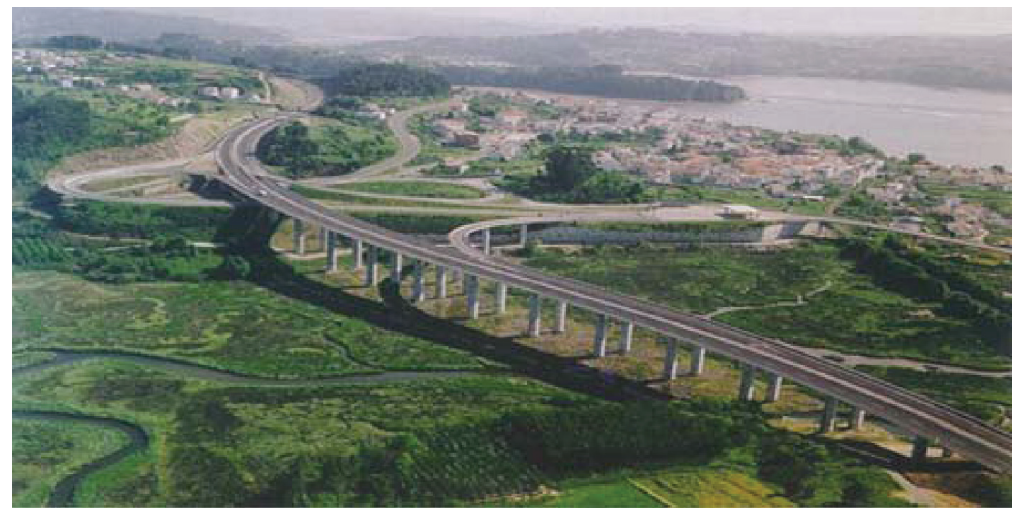

Figure 3: A viaduct across valley.

An embankment is visually dominant, blocking the view down the valley (Fig. 2).

- A kind of fragmentation of the land and large landtake is generated, resulting in minimization of connectivity into the landscape.

- Concrete structures (culverts, underpasses) appropriately seated have to be constructed in a way to allow watercourses.

- Appropriate use of earthworks by varying the gradients and use of vegetation and planting are significant measures to integrate the embankment with the surrounding landscape and provide the landscape connectivity.

- From an economic point of view, embankments are often preferred, especially when excessive excavation material has to be absorbed in construction.

Viaduct is a more expensive solution than an embankment but it is an ecologically preferable alternative [3]. It is preferred when the preservation of the particular valuable ecosystems and corridors found in river valleys outweighs the short-term economic benefit (Fig. 3).

From the environmental point of view, valleys are particular valuable ecosystems since valley bottoms are preferred routes for many animals, especially when there is a watercourse present. 
For wildlife, the existence and maintenance of their previous movement corridors is important, as it [4]:

- provides a minimization of landtake and fragmentation of landscape;

- allows watercourses and any existing nature conservation interest to continue under the structure;

- maintains connectivity for species movement;

- preserves ecosystems; and

- retains the view up and down the valley.

Additionally and alternatively, reinforced and stabilized embankments can be used, presenting advantages as well as drawbacks.

\section{ENVIRONMENT-FRIENDLY STRUCTURES AT FILL SECTIONS}

A comparative evaluation of fill sections structures through different parameters and criteria are shown in Table 1.

The optimum choice of the best adapted environment-friendly structure for fill sections may be derived from an appropriate constitutive graph shown on Fig. 4. The graph introduces three design criteria, embankment height at centerline, right-of-way factor, and environmental factor. The semi-empirical graph (Fig. 4) was drawn up from various case studies of motorway projects through plain or hilly terrain. The embankment height at centerline $(\Delta \mathrm{h})$ is introduced as a function of the road width $\left(=2 \mathrm{~B}_{\mathrm{o}}\right)$. For high structures, $\Delta \mathrm{h}>6 \mathrm{~B}_{\mathrm{o}}$, it is accepted that viaduct solution prevails. Both environmental and 'right-of-way' factors are given at a four-scale grade, related to the type of the surrounding area for each case. As a general rule, more rigorous constraints lead to a more costly and less annoying structure. Nevertheless, in the frame of a highway design study, local conditions are likely to lead to an alternative solution that is a mixed scheme, or a non-standard structure.

The graph prescribes three alternative solutions for the fill sections: ordinary embankment, reinforced or stabilized embankment, and viaduct. These fundamental factors, embankment height, the right-of-way, and the environment, are introduced to derive the best solution for the examined section following the scheme shown on the graph (Fig. 4). Chemically stabilized embankments are preferred

Table 1: Comparative properties of different fill sections structures.

\begin{tabular}{lcccc}
\hline & $\begin{array}{c}\text { Conventional } \\
\text { embankment }\end{array}$ & $\begin{array}{c}\text { Reinforced } \\
\text { embankment }\end{array}$ & $\begin{array}{c}\text { Stabilized } \\
\text { embankment }\end{array}$ & Viaduct \\
\hline Cost consideration & $* * *$ & $*$ & $* *$ & $\mathbf{0}$ \\
Right-of-way account & $*$ & $* *$ & $* *$ & $* * *$ \\
Engineering durability/ integrity & $*$ & $* *$ & $* *$ & $* * *$ \\
Environmental effects & $*$ & $*$ & $* *$ & $* * *$ \\
Energy consumption & $* * *$ & $*$ & $* *$ & $\mathbf{0}$ \\
\hline
\end{tabular}

$\mathbf{o}=$ poor, $*=$ fair, $* *=$ good, $* * *=$ excellent.

Conventional embankments should be constructed and preferred to other solutions whenever excavation products exceed and right-of-way constraints are negligible.

Stabilization of earth embankments is meant by secondary materials (fly-ash). Aesthetics are also taken into consideration within environmental effects. 


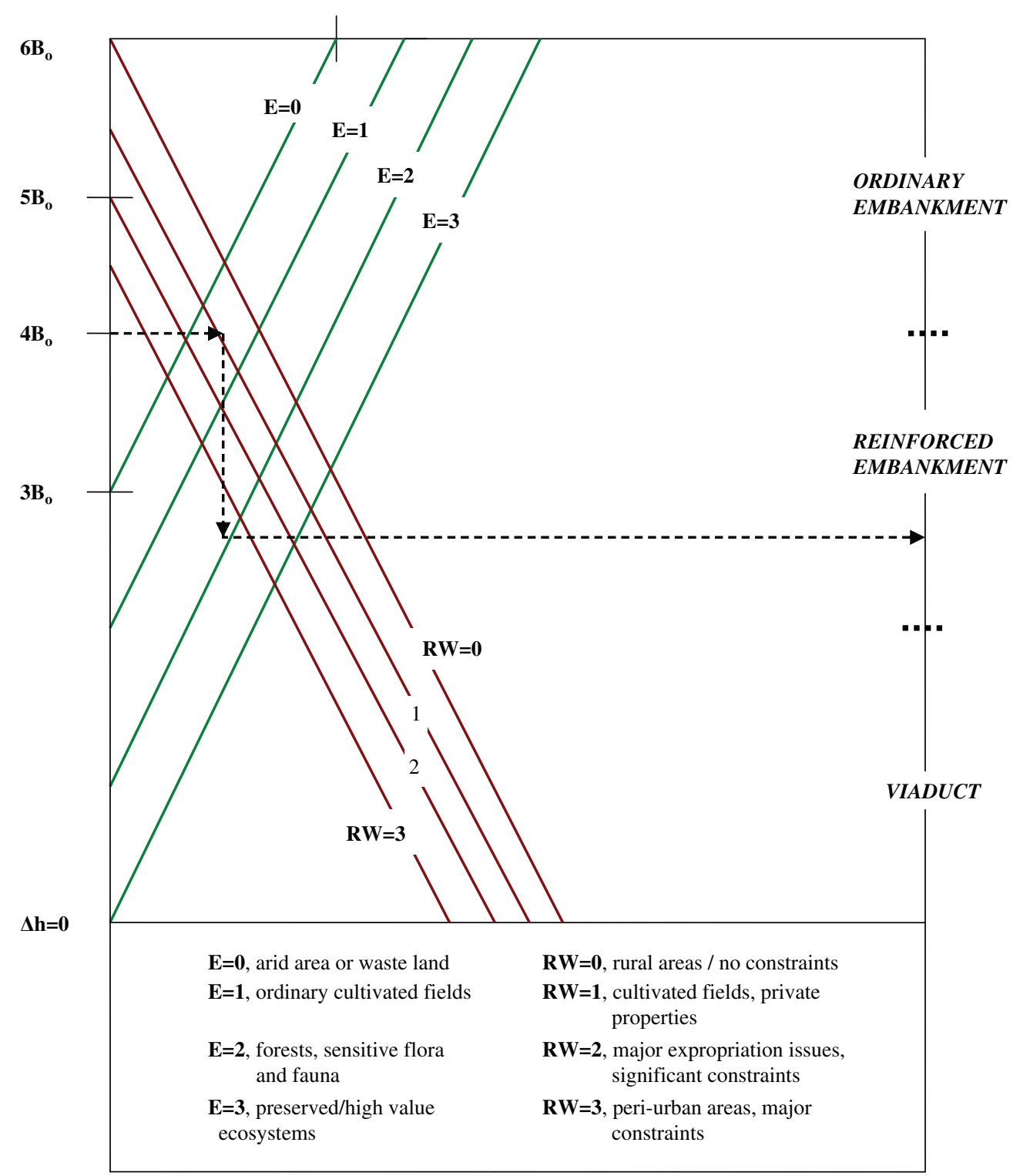

Figure 4: Optimum design graph for viaducts and embankments.

to reinforced earth embankments when stabilizing material (such as cement, lime, or fly-ash) is available at low cost [5].

\section{CUTTING}

Cutting is the usual solution for moderate depths of excavation, once the original land surface and everything built or growing on it is lost. Cuttings are usually constructed to a gradient usually varying from 1:1 to $3: 1$, depending on the geological composition of the constitutive materials. Low gradients (1:1 or less) provide long-term stability and better integration with natural landforms. They also allow 


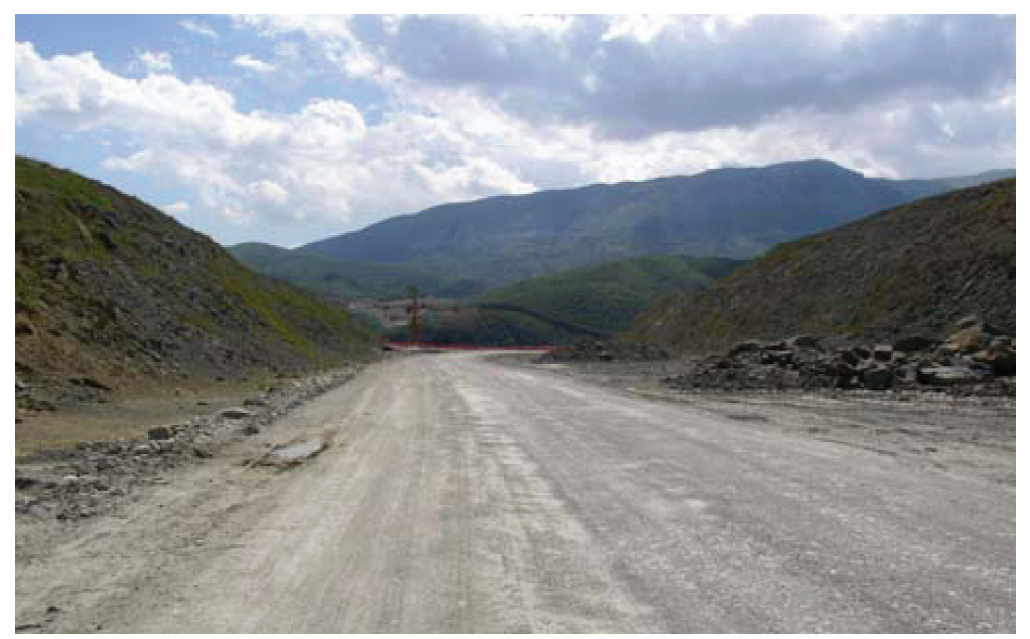

Figure 5: Cutting.

applications of better restoration methods with vegetation of seeding or planting. Grading out of cuttings to slopes smoother than 1:2 makes it easier to establish vegetation and provide opportunities for a variety of habitats to be created although it requires greater landtake. For gradients greater than $1: 1$, the use of hydroseeding techniques combined with geotextile stabilizing mattress achieve restoration of vegetation and stability (Fig. 5).

By contrast, a steep rock cut results in lesser amounts of surplus cut material but may itself be intrusive particularly when it creates a skyline notch that is more difficult to vegetate. In some rare cases, rock cut can provide an exciting expression in the landscape, a sense of space, driver interest, and nature conservation benefits. Shallow cutting with vertical retaining walls instead of earth slopes is another alternative solution, which is more expensive than traditional earthworks but provides less significant landtake.

In cases where a road section is intrusive, a false cutting is one of the best means of hiding the road from the surrounding landscape. It is appropriate where a natural cutting can not be achieved regarding to the ground of the topography. It has the added benefit of reducing the impact of noise. The best effect is obtained where the slope of cutting is returned to the adjacent land use, maintaining the character of existing views.

\section{BORED TUNNEL, 'CUT-COVER' AND 'COVER-CUT’ METHOD}

Decisions to build underground are made either because at-grade alternatives are totally infeasible or unacceptable or because the indirect financial, social, and environmental costs of such alternatives outweigh the generally much greater direct costs of underground construction. Engineers must seek design and construction techniques that minimize construction costs of underground structures depending on different parameters [6]:

- site morphology,

- geological and geotechnical conditions of rock,

- slope stability,

- surface water (rivers, irrigation canals) and groundwater,

- right-of-way constraints (buildings, infrastructures), 
- environmental constraints,

- safety aspects (risk of avalanches), and

- area seismic condition.

Among these parameters, environmental constraints and the technical aspects are the most important throughout the choice of suitable technical solution.

The construction of bored tunnel allows sites of high nature conservation value or settlements to remain undisturbed and are least damaging environmentally although the construction cost is high. Tunnels are very expensive and a thorough appraisal of the costs and environmental benefits is needed before a decision is made. Beyond a certain depth, depending on geology, groundwater and construction site, bored tunnel becomes an economic solution compared to an open cutting. The environmental integration of tunnel portal to the existing environment is an important issue in the design and construction of road. A modern portal architecture design is developed based on the philosophy of merging the portal into the landscape. This means that portals should be hidden as much as possible. The technological elements of the tunnel (ventilation system, water inflow control) have to be carefully assessed and monitored avoiding causing disturbance and pollution locally.

'Cut-and-cover' and 'cover-and-cut' are two methods for tunnel and roadway construction providing a desirable alternative to the open cutting. The advantage of these techniques consists in permitting that they permit the landscape to be restored over the line of the infrastructure. The methods have been widely used in rural areas in the following cases:

- where there are problems with stability conditions of cut slopes or a cut along the alignment is to be carried out in weak material;

- where there are environmental restrictions and the conservation of natural landscape is important; and

- where there are environmental regulations that require avoidance of open cuts or aesthetic degradation.

The basic stages of 'cut-and-cover' method is the preliminary excavation, the supporting of the open cut that would enable the safe construction of the tunnel, the concreting of the tunnel bore and then the placement of the cover fill in order to achieve the maintenance of the connectivity of the landscape. The 'cut-and-cover' technique is a simple to use construction method widely applied in both urban and rural tunneling projects. The main prerequisites for application of the method are the dominance of soft or weak ground conditions and/or of low overburden [7].

On the other hand, the method of 'cover-and-cut' consists of minimizing non-retained excavation. The construction process comprises six distinct stages: earthwork excavation and grading is preformed, the drilling of piles and the construction of slab, the construction of headbeams and the covering slab, the inside excavations, the construction of inner lining of the tunnel and finally the backfilling operations for environmental reasons [8].

Both methods are technically and economically optimal for tunneling at shallow depth. The soil profile should be constructed to match the adjoining profile in order to reproduce the hydrological characteristics as well as the physical structure, the species' habitats, and chemical properties of the original substrates. The reuse of original ground soils should be considered if they can be cut and stored in such a way as to minimize loosening of their proper structure. In Fig. 6 are shown 'Cutand-Cover' and 'Cover-and-Cut' tunnels in the Egnatia Motorway project, a $680 \mathrm{~km}$ long highway spanning the entire extent of northern Greece and cross-cutting the mountainous backbone of the country. 


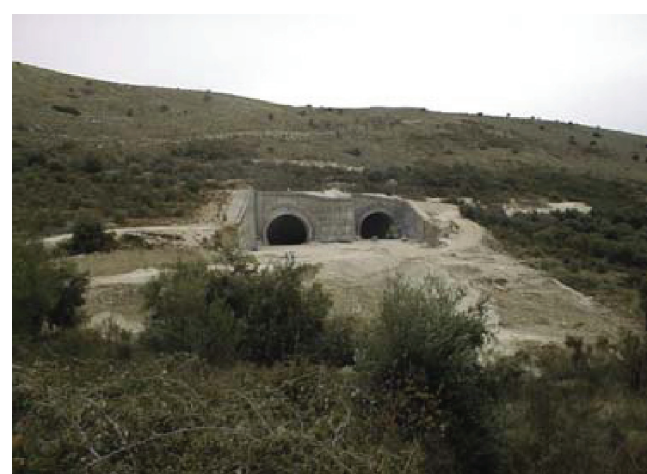

(a)

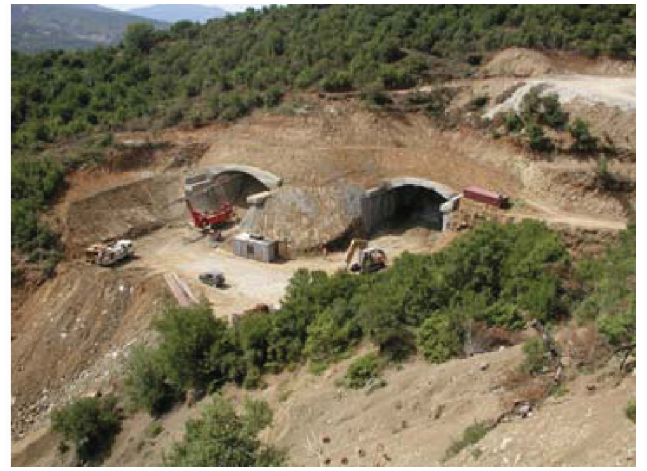

(b)

Figure 6: (a) Cut-and-cover method and (b) cover-and-cut method (Egnatia Motorway project).

Table 2: Comparative properties among different structures for cut sections.

\begin{tabular}{lcccc}
\hline & Cutting & Bored tunnel & Cut-cover & Cover-cut \\
\hline Cost consideration & $* * *$ & $\mathbf{0}$ & $* *$ & $*$ \\
Right-of-way account & $\mathbf{0}$ & $* * *$ & $*$ & $* *$ \\
Engineering effectiveness & $\mathbf{0}$ & $* * *$ & $*$ & $* *$ \\
Environmental effects & $*$ & $* * *$ & $*$ & $* *$ \\
Energy consumption & $* * *$ & $\mathbf{0}$ & $* *$ & $*$ \\
\hline
\end{tabular}

$\mathbf{o}=$ poor, $*=$ fair, $* *=$ good, $* * *=$ excellent.

\section{ENVIRONMENT-FRIENDLY STRUCTURES AT CUT SECTIONS}

A comparative appraisal of properties and characteristics of cut section structures through different parameters and criteria are shown in Table 2.

The selection of the optimum choice of the best environment-friendly cut sections is achieved graphically in Fig. 7. In this case, the criteria of the structure height at centerline and type of soil are introduced together with the environmental factor. The use of the graph is similar to the one presented at paragraph 5. These criteria are adequately introduced to yield the optimum design choice for the cut section.

\section{SUSTAINABLE HIGHWAY GEOSTRUCTURES}

Sustainable engineering design and construction, including earthworks structures, is a global trend. Essentially, sustainable highway geostructures are about minimizing the negative impacts and maximizing the positive impacts to achieve a balance in terms of environmental, economic, and social performance. Some of the specific areas of concern are life cycle assessment and energy efficient designs. Life Cycle Assessment is a tool which makes it possible to assess the environmental impact of a product, a process, or an activity, through evaluating the consumption of energy and materials as well as emissions generated. Under overall environment considered, in selecting materials and structures for highway earthworks, it is important to take into consideration the life-cycle environment impact of alternative structures, in order to determine the comparative environment-friendliness. 


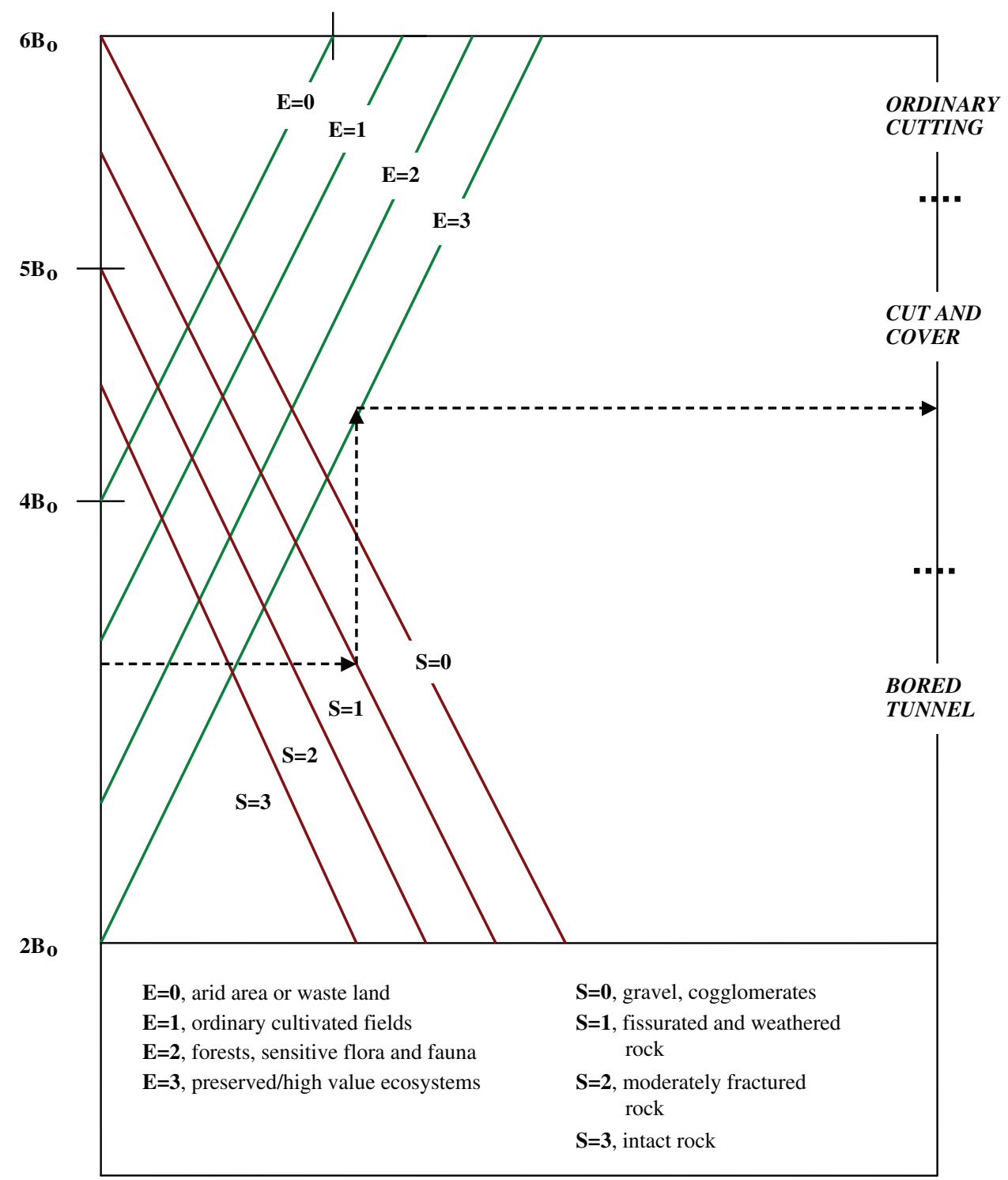

Figure 7: Optimum design graph for tunnels and cuttings.

Allowing the inventory analysis, it is questionable whether the concrete structures as tunnels and viaducts, implemented in highway construction, are absolutely environment-friendly and should be applied to replace cuttings and embankments of important offset.

\section{CONCLUSIONS}

The objective of route selection should be an optimal alternative for the road construction, which has both the minimum effect on landform and offers a high level-of-service. The form and the slopes of the existing topography determine the earthwork operations and the volume of cut and fills. 
The designing engineer, taking into consideration the basic rule of the volume of earthworks, suggests the construction of different geostructures most suitable to the topography. The assessment and the choice of the more environment-friendly geostructures is the result of the balancing out of technical, environmental, and economic parameters.

Accordingly, a sustainable development requires strengthening and broadening the education of engineers and finding innovative ways to achieve extension of the transportation infrastructure development while conserving and preserving natural resources.

\section{REFERENCES}

[1] Bochet E., Garcia-Fayos, Factors Controlling Vegetation Establishment and Water Erosion on Motorway Slopes in Valenci, Spain. Restoration Ecology, 12(2), pp. 166-174.

[2] Carpenter, T.G., Sustainable Civil Engineering, Volume 2, England: John Wiley, 2001.

[3] COST 341, Habitat fragmentation due to transportation infrastructure: a European handbook for identifying conflicts and designing solutions, 2003.

[4] Forman R.T.T., Road Ecology. Science and Solutions, Island Press: Washington, DC, 2003.

[5] IVL Swedish Environmental Research Institute, Life cycle assessment of road. A pilot study for inventory analysis, 2001.

[6] Peila D. \& Pelizza S., Criteria for technical and environmental design of tunnel portals, Tunneling and Underground Space Technology, 17(4), pp. 335-340, 2002.

[7] Sirtariotis N. \& Mouratidis A., Design considerations and application of the 'cut and cover' method in tunnel construction, 1st European Conference in Highway Earthworks, Paris, 2005.

[8] Mouratidis A., Lambropoulos, S., \& Sakoumpenta, E., The 'cover and cut' method in tunnel and roadway construction, 1st European Conference in Highway Earthworks, Paris, 2005. 